\title{
The Influence of Increased Renal Mass on Cardiovascular Function in Immature Dogs
}

\author{
WILLIAM J. H. CALDICOTT ${ }^{(33)}$ AND JULIE R. INGELFINGER \\ Departments of Radiology and Medicine, Children's Hospital Medical Center, and Harvard Medical School, Boston, \\ Massachusetts, USA
}

\begin{abstract}
Summary
Pediatric renal allograft recipients receive a relatively greater increase in renal mass than do adult recipients because the donors are usually adults. They also have a higher frequency of posttransplant hypertension and cardiovascular problems. Avoiding other variables common to both pediatric and adult patients including pre-existing hypertension and renal disease and the use of corticosteroids, renal mass was increased by up to $\mathbf{5 0 \%}$ in immature dogs by implanting large kidneys from adult dogs. Cardiovascular and renal function were studied before and after transplantation. Blood pressure was decreased in anesthetized mongrel pups at 2 hr and 3 days after surgery by 22 and $6 \mathrm{~mm} \mathrm{Hg}$, respectively; pressure was similarly reduced in conscious, chronically catheterized DLA-matched beagle pups maintained for 14 days, from 96.1 \pm 3.0 to $76.8 \pm 6.7 \mathrm{~mm} \mathrm{Hg}(P<0.001)$. Glomerular filtration rate was decreased at $2 \mathrm{hr}$ and 3 days, but was normal at 14 days. Cardiac output was reduced in four of five recipients at 2 hr but was unchanged at 3 days. Plasma volume was increased at 3 days in the mongrel dogs but was normal in the beagles both at 2 and 14 days. We conclude that an increase in renal mass of up to $50 \%$ by itself does not cause hypertension in the dog and that other factors may be implicated in pediatric allograft recipients.
\end{abstract}

\section{Speculation}

Since increase in renal mass per se does not cause hypertension in healthy immature pups, other factors may be responsible for posttransplant hypertension in pediatric renal allograft recipients. Likely candidates are pre-existing renal disease, pre-existing vascular disease, and the use of corticosteroids. Immature animals may respond differently than do adults to stimuli which contribute to posttransplant hypertension.

One obvious difference between adult and childhood renal transplant recipients is the relative mass of the allograft because most children receive transplants from adult donors. Hypertension develops in most children after renal transplantation in the early postoperative period, and more than $80 \%$ of recipients remain hypertensive, even in the absence of rejection or recurrent disease $(9,14,15,19)$. In contrast, the incidence of hypertension in adult renal allograft recipients is about $50 \%$ or less (1). It has been suggested that the lower cardiac output and arterial pressure in children may stimulate the large kidneys they receive to produce excess renin, or conversely, that the large kidney may alter cardiac output and/or extracellular volume. Many other factors may contribute to posttransplant hypertension, including the use of corticosteroids $(4,16,21-24,26,27)$, the presence of multiple kidneys (end-stage native or previously failed allograft) (1), rejection $(3,7,13,16,20,22-24,26,27)$ or recurrent disease $(16,19)$ and the development of vascular complications $(6,19)$ associated with transplantation; but these are common to adult and childhood allograft recipients.

To focus on relative renal mass and its effect on cardiovascular and renal function, we have increased renal mass by transplanting a large kidney from an adult dog into healthy immature recipients, intentionally avoiding other factors known to contribute to hypertension and alterations in cardiovascular function.

\section{MATERIALS AND METHODS}

Two sets of acute studies were performed on mongrel dogs in which observations were made with the animals anesthetized. So that observations could be extended for at least 2 wk after transplantation and to avoid allograft rejection, the effects of corticosteroids, and anesthesia, a further set of experiments were performed on DLA-matched beagle dogs in which chronic catheters were implanted. All animals were fed on normal dog chow and given free access to tap water. Surgical procedures and all studies in the mongrel dogs were performed under pentobarbital sodium anesthesia, induced with an initial $30 \mathrm{mg} / \mathrm{kg}$ dose and maintained with additional doses of the same agent. Kidneys were removed from adult donors, immediately perfused with a refrigerated solution $\left(4^{\circ} \mathrm{C}\right)$ of artificial extracellular fluid to which dextrose $(1.5 \%)$, heparin (1000 units $/ 100 \mathrm{ml})$, and xylocaine $(0.5 \mathrm{ml} / 100$ $\mathrm{ml}$ ) were added, and implanted into the recipients using end-toside anastomoses between the renal vessels and the abdominal aorta and inferior vena cava. The ureter was implanted into the recipient's bladder through a submucosal tunnel using standard anti-reflux technique.

\section{PROTOCOLS}

Acute Experiments in Mongrel Dogs. Eight donors weighed 21.3 $\pm 1.8 \mathrm{~kg}$ and nine recipient immature mongrel pups aged between 6 and 8 wk weighed $6.7 \pm 0.6 \mathrm{~kg}$. Cardiac output was measured by the thermodilution technique (8) (Instrumentation Laboratories) using polyethylene catheters (Blue Formocath; Becton, Dickinson) positioned in the left ventricle (inside diameter $=0.025$ inches) and the descending thoracic aorta (inside diameter $=0.045$ inches) from the brachial arteries using fluoroscopic guidance. The aortic catheter was used to monitor arterial pressure and as a conduit for the introduction of a 2 French thermistor probe. The left ventricular catheter was used to inject boluses of saline cooled to $0^{\circ} \mathrm{C}$. Glomerular filtration rate and effective renal plasma flow were calculated from standard clearances using inulin (25) and $p$ aminohippuric acid (29). A recording of renal blood flow was made with an electromagnetic flowmeter, with the flow probe placed directly on the renal artery (2). The probe was calibrated on the femoral artery of the donor at the end of each experiment. Plasma volume was measured using Evans blue dye (18) or ${ }^{125} \mathrm{I}$ labeled human serum albumin (17) as the tracer.

One-Day Protocol. In five animals, the posttransplant studies were completed on the day of surgery. The arterial catheters described above and venous catheters for infusion of drugs and intravenous fluids were introduced through forelimb vessels. Control clearances, cardiac output, and blood volume estimations were made while arterial pressure was monitored. The abdomens of the donor and recipients were then opened using long midline inci- 
Table 1. Comparison of donor and recipient mongrel dogs used in both I- and 3-day acute studies

\begin{tabular}{lcc}
\hline & Donor $(n=8)$ & Recipient $(n=9)$ \\
\hline Body wt (kg) & $21.3 \pm 1.8^{1}$ & $6.7 \pm 0.6^{2}$ \\
Single kidney wt (g) & $70.3 \pm 4.2$ & $29.3 \pm 2.2^{2}$ \\
Mean arterial pressure (mm Hg) & $127.8 \pm 7.8$ & $91.3 \pm 4.5^{2}$ \\
Cardiac output (liter/min) & $3.30 \pm 0.21$ & $1.50 \pm 0.19^{2}$ \\
Total peripheral resistance (mm & $41.0 \pm 2.3$ & $70.1 \pm 9.9^{3}$ \\
$\quad \mathrm{Hg} /$ liter/min) & & \\
Hematocrit $(\%)$ & $41.3 \pm 1.9$ & $30.0 \pm 0.9^{2}$ \\
\hline
\end{tabular}

\footnotetext{
${ }^{1}$ Mean \pm S.E.

${ }^{2} P<0.001$.

${ }^{3} P<0.02$.
}

sions, and the kidneys were mobilized. The native kidneys of the recipients were removed and weighed, and the abdominal aorta and inferior vena cava were mobilized. Blood flow in the adult kidney was measured with an electromagnetic flow probe in situ in the donor and after transplantation into the recipient. After transplantation, fluid losses were replaced by IV infusions of blood (from the donor) and either $0.9 \%$ sodium chloride or a solution containing $5 \%$ dextrose and $0.4 \%$ sodium chloride. Renal clearances, cardiac output, arterial pressure, and renal blood flow were studied at $2 \mathrm{hr}$ after transplantation.

Three-Day Protocol. Four pups and their donors were studied 2 days before transplantation, and recipients were restudied 3 days after transplantation. In these animals, sterile surgical techniques were used for introduction of the catheters, for the pretransplant studies, and for transplantation surgery. Cardiac output and arterial pressure measurements were made as in the 1-day protocol. Inulin clearances before transplantation were calculated using the infusion method (5), and glomerular filtration rate from each kidney was estimated by dividing total clearance by two. In addition, these animals were placed in metabolic cages for 24-hr urine collections both before transplantation and for the $24 \mathrm{hr}$ before the follow-up study 3 days after surgery, and plasma volume was measured.

Chronic Experiments in Related, DLA-Matched Beagle Dogs. These dogs came from a closed colony of dogs bred at the Mary Imogene Bassett Hospital (Cooperstown, NY). Two adult donors were 10 to 11 months old and a single immature donor was 3 months old. The six recipients were 3 months old. They were trained to stand in a harness, and all measurements were made without anesthesia using chronically implanted polyvinyl chloride catheters (Tygon microbore; Norton; inside diameter $=0.040$ inches). A catheter was introduced into either the descending throacic aorta, through a left thoracotomy, or into the abdominal aorta and the inferior vena cava via the left renal artery and vein, after left nephrectomy. The lines were passed through subcutaneous tunnels to an exit site between the scapulae, fixed to the skin, and protected by a dog jacket. Lines were filled with heparin and flushed daily. Renal clearance of inulin was estimated by the infusion method (5) after infusing the inulin for at least $90 \mathrm{~min}$ for equilibration. Twenty-four-hr urine collections were made for sodium excretion with the dogs in metabolic cages while receiving Purina dog chow, which provides about $2 \mathrm{mEq}$ of sodium per $\mathrm{kg}$ body weight in $24 \mathrm{hr}$, and tap water ad libitum. Blood samples were taken at the end of the collection period for plasma renin activity; plasma was separated in a refrigerated centrifuge and stored frozen until assayed using the double antibody radioimmunoassay method of Emanuel et al. (6). Arterial pressure was monitored daily, and plasma renin activity, $24 \mathrm{hr}$ urinary excretion of sodium, renal clearances of inulin, and blood volume were estimated before transplant surgery and at $24 \mathrm{hr}, 7$ days, and 2 wk after surgery.

One pair of recipients received adult kidneys which each weighed approximately $65 \mathrm{~g}$. At nephrectomy $3 \mathrm{wk}$ before transplantation, their left kidneys weighed 16.8 and $18.7 \mathrm{~g}$, and their remaining right kidneys, removed on the day of transplantation, weighed 30.0 and $36.8 \mathrm{~g}$. A second pair of recipients, whose native kidney weights are not known, received adult kidneys weighing approximately $55 \mathrm{~g}$. A third pair of recipients, with their native kidneys in situ, had their renal mass increased by approximately $50 \%$ by the transplantation of an additional kidney from a $5-\mathrm{kg}$, 3-month-old immature donor. The two adult donors weighed 15.6 and $17.5 \mathrm{~kg}$, and the average weight of the six recipients was 5.4 $\pm 0.4 \mathrm{~kg}$.

Data were analysed using Student's $t$ test or Fisher Exact test for nonparametric data. The null hypothesis was rejected when a $P$ value of 0.05 or less was achieved. Mean values have been presented with the standard error of the mean as the index of dispersion.

\section{RESULTS}

\section{ACUTE EXPERIMENTS IN MONGREL DOGS}

The donors, selected for markedly greater body weight, also had significantly greater drained kidney weight, mean blood pressure, cardiac output, and hematocrit, but lower calculated peripheral vascular resistance, than the immature recipients (Table 1).

One-Day Protocol. At $2 \mathrm{hr}$ after renal transplantation, arterial pressure in the five immature recipients had fallen from a pretransplant level of $87.8 \pm 7.1$ to $65.8 \pm 2.6 \mathrm{~mm} \mathrm{Hg}(P<0.05)$ (Fig. 1). Cardiac output fell in four of five recipients, but for the group, there was no significant difference $[1.24 \pm 0.24$ to $1.00 \pm 0.24$ liters/min $(P>0.5)]$, and there was no net change in calculated

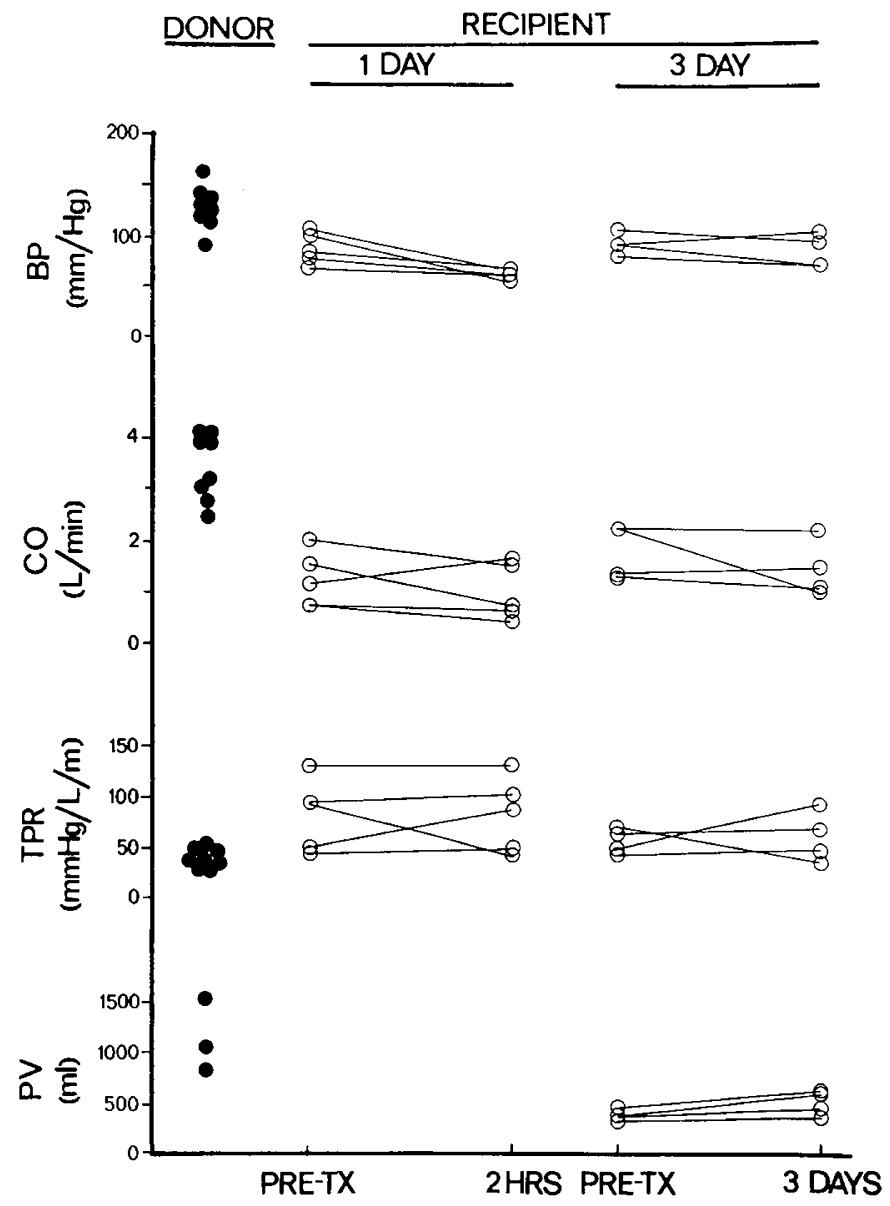

Fig. 1. Control values in donors and recipients before transplantation $(P R E-T X)$ and in two sets of recipients studied at $2 \mathrm{hrs}$ and 3 days posttransplantation, respectively. Cardiovascular function in acute protocols [blood pressure $(B P)$, cardiac output $(C O)$, total peripheral resistance $(T P R)$, and plasma volume $(P V)]$ are depicted as $\bullet$ (donors) and $\bigcirc$ (recipients). 
total peripheral resistance in the recipients (pretransplant, $87.1 \pm$ $15.9 \mathrm{~mm} \mathrm{Hg} /$ liter/min; posttransplant $81.7 \pm 16.7 \mathrm{~mm} \mathrm{Hg} /$ liter/ min). Compared to values obtained in situ in the donor at $2 \mathrm{hr}$ after transplantation, there was no significant change in blood flow to the transplanted kidney (in situ in the donor; $210.9 \pm 17.8$ $\mathrm{ml} / \mathrm{min}$; posttransplant, $152.3 \pm 32.7 \mathrm{ml} / \mathrm{min} ; P>0.2$ ), or in renal vascular resistance (in situ in the donor, $597 \pm 52.0 \mathrm{~mm} \mathrm{Hg} / \mathrm{liter} /$ min; posttransplant, $513.0 \pm 107.8 \mathrm{~mm} \mathrm{Hg} / \mathrm{liter} / \mathrm{min}$ ). Glomerular filtration rate was decreased from $45.4 \pm 3.8 \mathrm{ml} / \mathrm{min}$ in the donor to $10.1 \pm 3.2 \mathrm{ml} / \mathrm{min}(P<0.001)$ after transplantation (Fig. 2).

Three-Day Protocol. At 3 days after transplantation in the four recipients, there were small but insignificant decreases in both mean arterial pressure $(95.8 \pm 5.1$ to $89.5 \pm 8.1 \mathrm{~mm} \mathrm{Hg})$ and cardiac output $1.81 \pm 0.26$ to $1.61 \pm 0.31$ liters $/ \mathrm{min}$ ) and no change in calculated total peripheral resistance $(55.5 \pm 6.3$ to 62.3 $\pm 12.7 \mathrm{~mm} \mathrm{Hg}$ ) (Fig. 1). In each recipient, there was an increase in plasma volume $(391 \pm 23 \mathrm{ml}$ to $503 \pm 53 \mathrm{ml} ; P<0.02)$ and a decrease in hematocrit $(34.5 \pm 2.9$ to $26.8 \pm 2.0 \% ; P<0.005)$ (Fig. 1). Perfusion and function in the transplanted kidney, compared to pretransplant in situ measurements in the donor, had markedly changed by 3 days after transplantation (Fig. 2). Renal blood flow had fallen from $198.5 \pm 25.0$ to $72.5 \pm 15.5 \mathrm{ml} / \mathrm{min}(P<0.001)$, and glomerular filtration rate had fallen from $41.2 \pm 7.7$ to 13.7 $\pm 0.9 \mathrm{ml} / \mathrm{min}(P<0.001)$. Urine flow at 3 days was well maintained, averaging $160 \pm 7 \mathrm{ml} / 24 \mathrm{hr}$ in the 3 dogs in which it was measured.

\section{CHRONIC EXPERIMENTS IN DLA-MATCHED BEAGLE DOGS}

As in the case of the acute experiments, mean arterial pressure in the recipients after transplantation fell from a control level of $96.1 \pm 3.0$ to $78.5 \pm 4.1 \mathrm{~mm} \mathrm{Hg}$ by day 1 , and in the five survivors to $86.0 \pm 3.9$ and $76.8 \pm 6.7 \mathrm{~mm} \mathrm{Hg}(P<0.001)$ by days 5 and 14 , respectively (Fig. 3). In the six recipients, there was an insignificant fall in glomerular filtration rate from a pretransplant level of 40.1 \pm 3.4 to $28.7 \pm 5.8 \mathrm{ml} / \mathrm{min}(P>0.1)$ by 1 to 2 days after

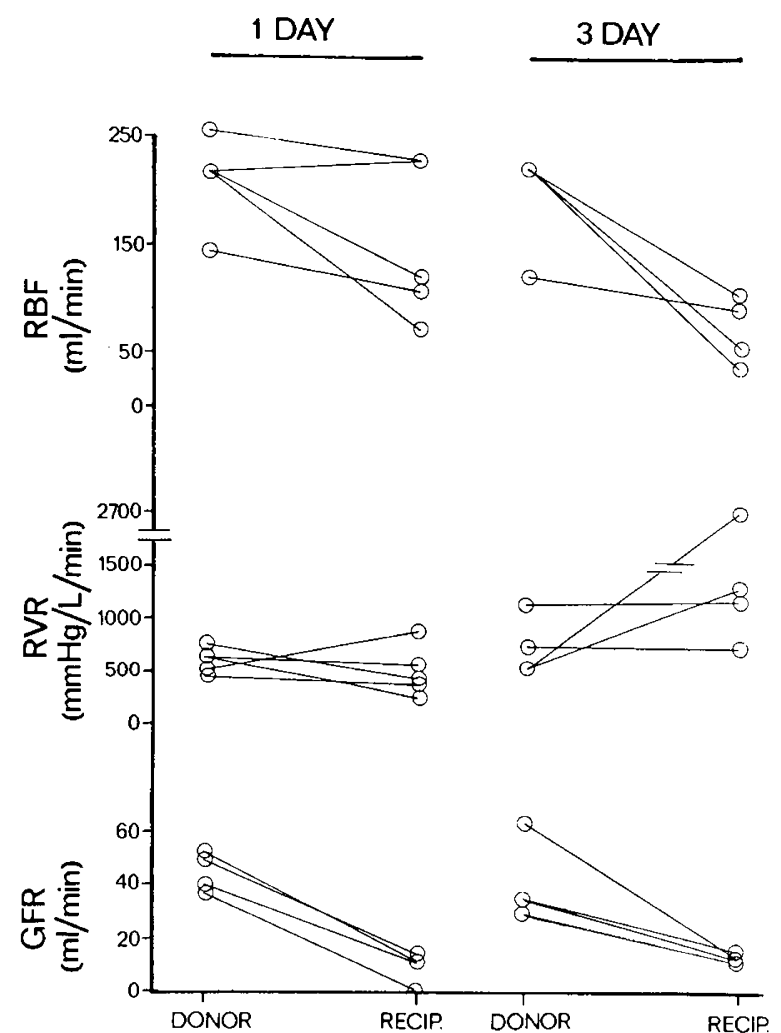

Fig. 2. Renal function in acute studies. Renal blood flow $(R B F)$, renal vascular resistance $(R V R)$, and glomerular filtration rate $(G F R)$ all shown pretransplant in the donors and compared to posttransplant in two sets of recipients studied at $2 \mathrm{hr}$ and 3 days posttransplant.
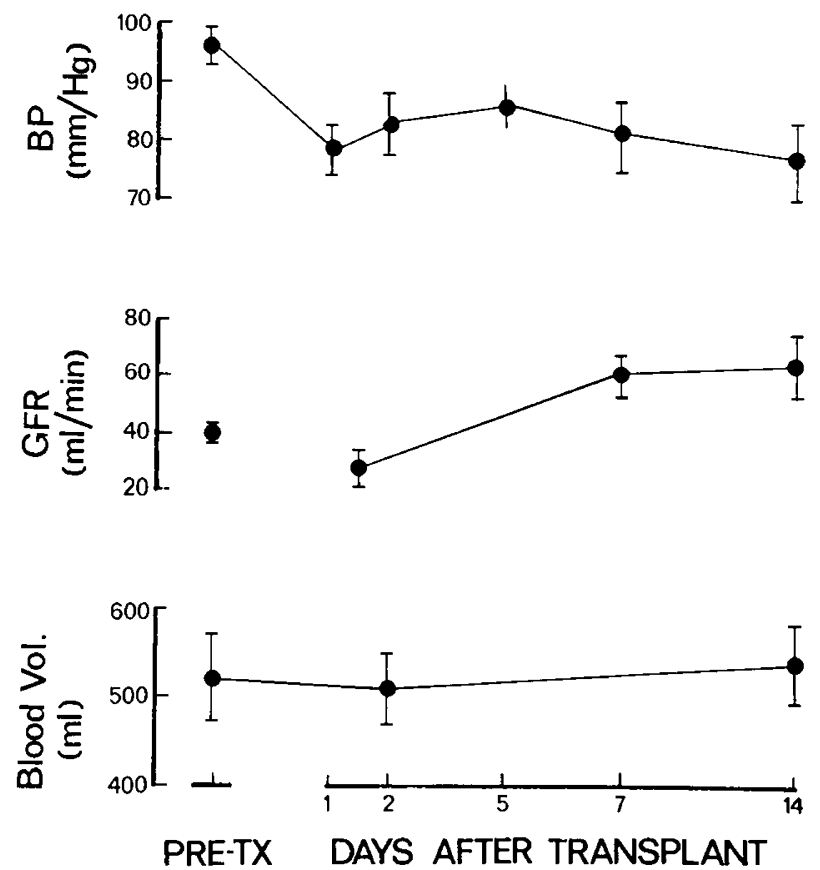

Fig. 3. Two-wk course of blood pressure $(B P)$, glomerular filtration rate $(G F R)$ and blood volume (Blood Vol.) are shown in DLA-matched pups studied in the conscious state before (PRE-TX) and after transplantation.

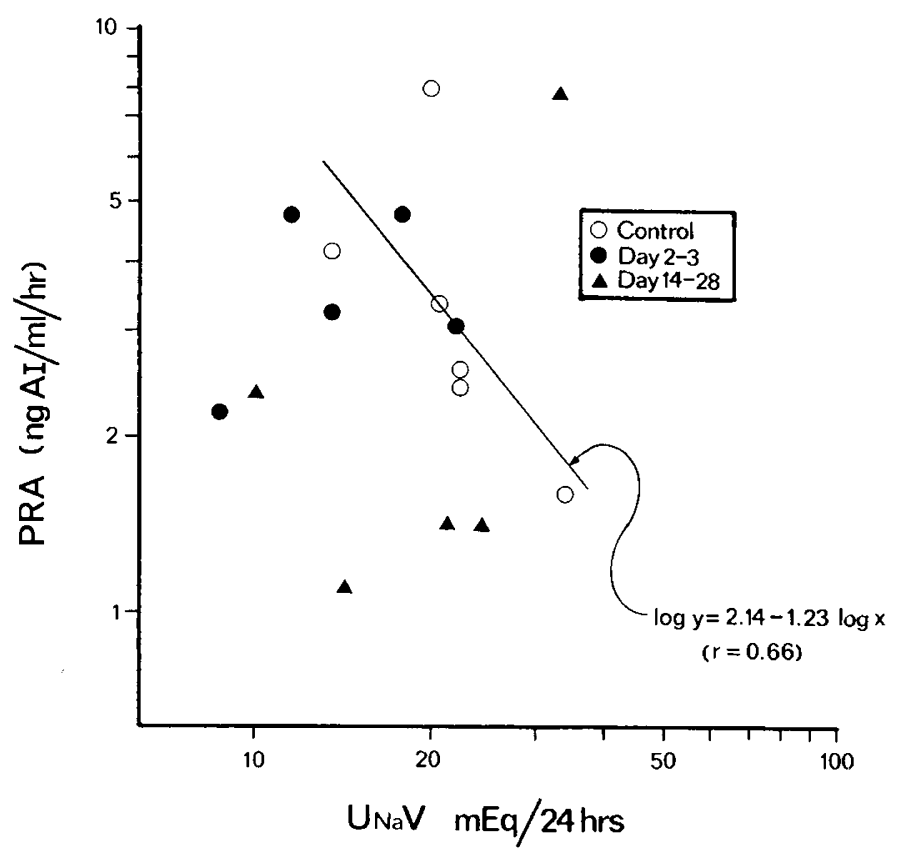

Fig. 4. Relationship between plasma renin activity $(P R A)$ and $24-\mathrm{hr}$ sodium excretion $\left(U_{\mathrm{NA}} V\right)$ in DLA-matched recipients. Regression line is for control values before transplantation $(O)$., , values after transplantation.

transplantation and in four of five survivors in which it was measured an increase during the next $2 \mathrm{wk}$ to $61.1 \pm 7.1 \mathrm{ml} / \mathrm{min}$ (Fig. 3). There was no change in blood volume (Fig. 3) and an insignificant decrease in hematocrit from the control value of 32.8 \pm 1.0 to $28.6 \pm 2.5$ by 14 days. Urine flow was $315 \pm 86 \mathrm{ml} / 24 \mathrm{hr}$ on day 3 in five of the dogs. One recipient was maintained for 4 months after transplantation during which time she thrived, increasing her body weight from 6.5 to $9.6 \mathrm{~kg}$. Compared to pretransplant values, glomerular filtration rate increased from 28 to $64 \mathrm{ml} / \mathrm{min}$, blood volume increased from 577 to $800 \mathrm{ml}$, hematocrit 
was unchanged at $36 \%$, and mean arterial pressure had decreased from 91 to $83 \mathrm{~mm} \mathrm{Hg}$.

The relationship between urinary sodium excretion $(x)$ and plasma renin activity (y) in the recipients before transplantation is shown in Fig. 4; there was no increase in plasma renin activity after transplantation; in fact by 2 to $4 \mathrm{wk}$, plasma renin activity in four of five recipients was below that predicted for comparable levels of urinary sodium excretion.

\section{DISCUSSION}

The effect of increased renal mass on cardiovascular function has not been the subject of previous investigations, although renal function has been measured in studies of renal hypertrophy (28). For example, Silber and Malvin (28) have shown that adult male rats which receive a third kidney have glomerular filtration rates and renal plasma flows $50 \%$ greater than those of control levels. These investigators also transplanted hypertrophied kidneys from previously uninephrectomized donors into previous uninephrectomized recipients so that recipients had two hypertrophied kidneys. Subsequently, the hypertrophied kidneys returned to the normal adult size. However, their studies did not look at blood pressure changes, cardiac function, or vascular reactivity, nor did they examine transplantation of an adult kidney or kidneys into immature animals.

In the present study, increasing renal mass in immature dogs failed to induce the hypertension which occurs in pediatric renal transplant patients. There are several possible explanations. The approximate 20 to $50 \%$ increase in renal mass which we achieved in dogs is considerably less than the increase which results from transplantation of an adult kidney into an essentially anephric child. Alternatively, the original hypothesis may have been in error; a large kidney alone does not cause hypertension, and other factors, such as the use of corticosteroids, pre-existing renal disease, or hypertension, with or without the addition of increased renal mass, may be more important determinants of the level of arterial pressure after renal transplantation. However, these factors are common to adult and pediatric transplant patients and would not explain the greater frequency of posttransplant hypertension in children. Alternatively, species differences may exist which influence cardiovascular response to renal transplantation.

Reasons for the pressure decreases in the present study have not been completely defined. In the dog, studied on the day of surgery, pressure and renal perfusion were, in part, volume dependent. However, although renal blood flow could be increased by intravenous transfusions to levels only slightly less than normal for the kidney, in situ, in the donor, blood pressure remained markedly depressed. In a large denervated kidney not subject to sympathetic activity, active autoregulatory vasodilatation in response to reductions in perfusion pressure may have limited the animal's ability to respond to volume depletion and the stress of surgery. Pressure was better maintained at 3 days in the acute model, possibly due to a significant increase in plasma volume. We do not have an adequate explanation for the decrease in blood pressure which persisted in healthy growing dogs for as long as 4 months after transplantation. Inasmuch as pre-existing renal disease, allograft rejection, and the use of corticosteroids and anesthesia were avoided in these animals, the pressure decrease must have been related to the increase in renal mass. Age and maturity of the donor and allograft were not important because two of the chronic recipients, with both native kidneys in situ, had their renal mass increased by the addition of a third kidney from an immature donor, and they also became and remained relatively hypotensive. The pressure could not be explained on the basis of changes in cardiac output or plasma volume.

The reduced perfusion pressure in the recipients did not result in elevation of plasma renin activity; actually, in four of five chronic recipients, levels of plasma renin activity after transplantation were lower than predicted on the basis of the relationship between plasma renin activity and 24-hr urinary sodium excretion, established for these animals before surgery. This may have reflected the influence of renal denervation on renin production by the kidney $(10,30)$.

Renal blood flow was decreased in the acute model studied at 3 days after surgery. The simultaneous marked reduction in glomerular filtration rate, more marked in the acute than the chronic model, may have been due either to the reduction in arterial pressure to levels close to the lower limit of the autoregulatory range for glomerular filtration rate in the adult dog kidney (11) or to transient parenchymal damage (12). Parenchymal damage is the more likely explanation because (1) although glomerular filtration rate was reduced, urinary flow was normal or increased; and (2) in spite of persistent reductions in arterial pressure between 3 and 14 days in the chronic model, glomerular filtration rate returned to normal.

Thus, the immature dog without pre-existing renal or vascular disease does not develop the cardiovascular complications of renal transplantation which are almost universally seen in pediatric patients. Further studies will be necessary to test the influence of established renal or hypertensive disease and species differences on cardiovascular function after renal transplantation.

\section{REFERENCES AND NOTES}

1. Belzer, F. O., Schweitzer, R. T., Holliday, M., Potter, D., and Kountz, S. L.: Renal homotransplantation in children. Am. J. Surg., 124: 270 (1972).

2. Caldicott, W. J. H., Hollenberg, N. K., and Abrams, H. C.: Change of response of renal vascular bed to contrast media. Invest. Radiol., 5: 539 (1970).

3. Cerelli, J., Evans, W. E., and Sotos, J. F.: Renal transplantation in infants and children. Transplant. Proc., 4: 633 (1972).

4. Cohen, S. L.: Hypertension in renal transplant recipients. Role of bilateral nephrectomy. Br. Med. J., 3: 78 (1973).

5. Cole, B. R., Giangiacomo, J., Ingelfinger, J. R., and Robson, A. M.: Inulin and PAH clearances by infusion methods to assess renal function. N. Engl. J. Med., 287: 1109 (1972)

6. Emanuel, R. L., Cain, J. P., and Williams, G. H.: Double antibody radioimmunoassay of renin activity and angiotensin II in human peripheral plasma. J. Lab. Clin. Med., 81: 632 (1973).

7. Fine, R. N.: Renal transplantation in children. Simep. Editions, Villeurbanne, France, International Course on Transplantation (1973)

8. Freed, M. D., and Keane, W. F.: Cardiac output measured by thermodilution in infants and children. J. Pediatr., 92: 39 (1978).

9. Gonzales, L. L., Martin, L., West, C. D., Spitzer, R., and McEnery, P.: Renal homotransplantation in children. Arch. Surg., 101: 232 (1970).

10. Grandjean, B., Annat, G., Vincente, M., and Sassand, J.: Influence of renal nerves on renin secretion in the conscious dog. Pflügers Arch. Eur. J. Physiol., 373: 161 (1978).

11. Guyton, A. C.: Textbook of Medical Physiology. Ed. 5, p. 445 (W. B. Saunders Co., Philadelphia, 1976).

12. Guyton, A. C.: Textbook of Medical Physiology. Ed. 5, p. 504 (W. B. Saunders Co., Philadelphia, 1976).

13. Hulme, B., Kenyon, J. R., and Owen, N.: Renal transplantation in children. Am. J. Dis. Child., 47: 486 (1972).

14. Ingelfinger, J. R., Lazarus, J. M., Levey, R. H., Lowrie, E. G., Topor, M., and Grupe, W. E.: Hypertension in pediatric renal transplant patients. Pediatr. Res., 9: 376 (1975).

15. Ingelfinger, J. R., Levey, R. H., and Grupe, W. L.: Posttransplant hypertension in the absence of rejection or recurrent disease. Pediatr. Res., 12: 543 (1978).

16. Linas, S. L., Miller, P. D., McDonald, K. M., Stables, D. P., Katz, F., Weil, R., and Schrier, R. W.: The renin angiotensin system in post-transplant hypertension. N. Engl. J. Med., 298: 1440 (1978).

17. Linderkamp, O., Holthausen, H., Siefert, J., Butenandt, I., and Riegel, K. P.: Accuracy blood volume estimation in critically ill children during ${ }^{125}$ I-labelled albumin and ${ }^{51} \mathrm{Cr}$-labelled red cells. Eur. J. Pediatr., 125: 143 (1977).

18. Linderkamp, O., Mader, T., Butenandt, O., and Riegel, K. P.: Plasma volume estimation in severely ill infants and children using a simplified Evans Blue method. Eur. J. Pediatr., 125: 135 (1977).

19. Malekzadeh, M. D., Brennan, L. P., Payne, V. C., and Fine, R. W.: Hypertension after renal transplantation in children. J. Pediatr., 86: 370 (1975).

20. McDonald, J. C., Bethea, M. C., Lindsey, E. S., Gonzalez, F. M., and Garbus, S B.: Hypertension and renin in human renal transplantation. Ann. Surg., 179: 580 (1974).

21. Murray, J. E., Merrill, J. P., and Harrison, J. H.: Kidney transplantation between seven pairs of identical twins. Ann. Surg., 148: 343 (1958).

22. Najarian, J. S., Simmons, R. L., Tallent, M. B., Kjellstrand, C. M., Buselmeier, T. J., Vernier, R. L., and Michael, A. F.: Renal transplantation in infants and children. Ann. Surg., 174: 583 (1971).

23. Papadimitriou, M., Chisolm, G. D., and Shackman, R.: Hypertension in patients on regular hemodialysis and after renal allotransplantation. Lancet, $1: 902$ (1969).

24. Popovtzer, M. M., Pinnagera, W., Katz, F. H., Corman, J. L., Robinette, J., Lanois, B., Halgrimson, C. C., and Starzl, T. E.: Variations in arterial blood pressure after kidney transplantation. Relation to renal function, plasma renin activity, and the dose of prednisone. Circulation, 47: 1297 (1973). 
25. Roe, J. H., Epstein, J. H., and Goldstein, N. P.: A photometric method for the determination of inulin in plasma and urine. J. Biol. Chem., 178: 839 (1945).

26. Sampson, D., and Albert, D. J.: Alternate-day therapy with methylprednisolone after renal transplantation. J. Urol., 109: 345 (1973).

27. Sampson, D., Kirdani, R. Y., Sandberg, A. A., and Murphy, G. P.: The aetiology of hypertension after renal transplantation in man. Br. J. Surg., 61: 819 (1973).

28. Silber, S., and Malvin, R. L.: Compensatory and obligatory renal growth in rats. Am. J. Physiol., 226: 114 (1974).

29. Smith, H. W., Finkelstein, N., Aliminosa, L., Crawford, B., and Graber, M.: The renal clearances of substituted hippuric acid derivatives and other aromatic acids in dog and man. J. Clin. Invest., 24: 388 (1945).

30. Thames, M. D., and DiBona, G. F.: Renal nerves modulate the secretion of renin

Copyright (C) 1981 International Pediatric Research Foundation, Inc. 0031-3998/81/1506-0935\$02.00/0 mediated by nonneural mechanisms. Circ. Res., 44: 645 (1979).

31. It is a pleasure to acknowledge the assistance of A. Kelton, S. Ellis, M. Kuber, and D. Sucher.

32. This work was done during the tenure of a research grant-in-aid from the American Heart Association, Greater Boston Massachusetts Division, No. 13$517-778$, and was supported by a grant from the Charles H. Hood Foundation.

33. Requests for reprints should be addressed to: W. J. H. Caldicott, M.B., B.S., Kresge Foundation Laboratory, Department of Radiology, Children's Hospital Medical Center, 300 Longwood Avenue, Boston, MA 02115 (USA).

34. Received for publication March 17, 1980.

35. Accepted for publication October 20, 1980. 